\title{
PENGARUH KOMPENSASI DAN RESILIENSI TERHADAP KEPUASAN KERJA KARYAWAN
}

\author{
Utomo Kevin Tonnisen ${ }^{1}$, Mei $\mathrm{Ie}^{2}$ \\ ${ }^{1}$ Jurusan Manajemen, Universitas Tarumanagara Jakarta \\ Email:lordkiddie@yahoo.com \\ 2 Jurusan Manajemen, Universitas Tarumanagara Jakarta \\ Email:meii@fe.untar.ac.id
}

Masuk : 21-04-2020, revisi: 28-04-2020, diterima untuk diterbitkan : 29-04-2020

\begin{abstract}
ABSTRAK
Tujuan penelitian ini adalah untuk mengetahui ada tidaknya pengaruh kompensasi terhadap kepuasan kerja karyawan dan pengaruh resiliensi terhadap kepuasan kerja karyawan. Kepuasan kerja karyawan merupakan salah satu variabel yang paling banyak diteliti. Kepuasan kerja didefinisikan sebagai suatu keadaan emosional dialami karyawan, yang bersifat menyenangkan atau bersifat positif. Kepuasan kerja pada umumnya yang dihasilkan dari penilaian karyawan terhadap pengalaman kerja atau pekerjaannya. Dengan demikian, kepuasan kerja menunjukkan sikap positif umum karyawan terhadap pekerjaannya. Apabila karyawan merasa adanya kepuasan kerja, maka karyawan tersebut dapat lebih termotivasi untuk menghasilkan kinerja yang lebih baik. Kepuasan kerja dipengaruhi oleh banyak variabel. Dalam penelitian ini, variabel yang akan diteliti pengaruhnya terhadap kepuasan kerja karyawan adalah kompensasi dan resiliensi. Kompensasi merupakan total penghargaan atau hadiah yang diberikan perusahaan sebagai pembayaran atas hasil pekerjaan karyawan, sedangkan resiliensi merupakan suatu konsep yang menunjukkan kemampuan seseorang untuk mengatasi dan beradaptasi terhadap masa-masa sulit yang dihadapinya. Metode analisis data menggunakan Structural Equation Model (SEM) dengan alat analisis SmartPLS 3.0. Sampel diambil dengan metode non-probability sampling dan teknik purposive sampling. Sampel dalam penelitian sebanyak tigapuluh orang karyawan dengan kriteria merupakan karyawan yang masih aktif bekerja dan memiliki masa kerja minimal satu tahun. Hasil pengujian hipotesis menunjukkan bahwa adanya pengaruh positif kompensasi terhadap kepuasan kerja karyawan dan adanya pengaruh positif resiliensi terhadap kepuasan kerja karyawan. Kesimpulan penelitian ini adalah kompensasi berpengaruh terhadap kepuasan kerja dan resiliensi juga berpengaruh terhadap kepuasan kerja. Keterbatasan penelitisan ini adalah jumlah sampel yang sedikit sehingga pada penelitian mendatang, jumlah sampel penelitian dapat lebih ditingkatkan.
\end{abstract}

Kata Kunci: kepuasan kerja, kompensasi, resiliensi

\begin{abstract}
The purpose of this study is to determine whether there is an effect of compensation on employee job satisfaction and the effect of resilience on employee job satisfaction. Employee job satisfaction is one of the most widely studied variables. Job satisfaction is defined as an emotional state experienced by employees, which is fun or positive. Job satisfaction in general results from employee evaluations of work experience or work. Thus, job satisfaction shows the general positive attitude of employees towards their work. If employees feel job satisfaction, then the employee can be more motivated to produce better performance. Job satisfaction is influenced by many variables. In this study, the variables that will be examined for their effects on employee job satisfaction are compensation and resilience. Compensation is the total award or prize given by the company as payment for the work of employees, while resilience is a concept that shows a person's ability to overcome and adapt to the difficult times they face. The data analysis method uses Structural Equation Model (SEM) with SmartPLS 3.0 analysis tools. Samples were taken by the non-probability sampling method and purposive sampling technique. The samples in this study were thirty employees with the criteria are employees who are still actively working and have a minimum working period of one year. The results of hypothesis testing indicate that there is a positive effect of compensation on employee job satisfaction and a positive effect of resilience on employee job satisfaction. The conclusion of this study is that compensation has an effect on job satisfaction and resilience also has an effect on job satisfaction. The limitation of this research is the small number of samples so that in future studies, the number of research samples can be further increased.
\end{abstract}

Keywords: job satisfaction, compensation, resilience 


\section{PENDAHULUAN}

\section{Latar Belakang}

Sumber daya manusia (karyawan) yang berkualitas yang diperlukan oleh perusahaan untuk memenangkan persaingan usaha adalah karyawan yang mempunyai keterampilan sesuai dengan tuntutan pekerjaan yang ada serta memiliki integritas dan profesionalisme dalam melaksanakan pekerjaannya.

Hal penting yang perlu diperhatikan oleh perusahaan untuk mempertahankan karyawan yang berkualitas tersebut adalah perusahaan perlu menciptakan bahkan meningkatkan kepuasan kerja karyawan. Karyawan yang memiliki kepuasan kerja cenderung mempunyai produktivitas yang lebih tinggi, mampu bekerja secara mandiri serta mampu bersaing secara sehat di dalam dunia kerja. Karyawan yang memiliki kepuasan kerja akan memberikan segenap tenaga, semangat dan kemampuannya untuk menghasilkan kinerja yang baik bagi perusahaannya.

Kepuasan kerja dipandang sebagai sikap karyawan terhadap pekerjaannya, organisasi, lingkungan kerja fisik dan sosial, serta imbalan (kompensasi) yang diterimanya (Yousef, 2017; dalam Albawi, 2019). Locke (1976; dalam Kong et.al., 2018) mengemukakan bahwa kepuasan kerja menggambarkan suatu keadaan emosional yang bersifat menyenangkan atau bersifat positif dari seorang karyawan. Kepuasan kerja tersebut pada dasarnya dihasilkan dari penilaian karyawan terhadap pengalaman kerja atau pekerjaannya. Dengan demikian, kepuasan kerja merujuk pada sikap positif umum yang dimiliki karyawan terhadap pekerjaannya.

Luthans (2006) mengemukakan bahwa ada lima faktor yang dapat mempengaruhi kepuasan kerja, yaitu: gaji (upah), pekerjaan itu sendiri, promosi, rekan kerja, dan pengawasan (supervisi). Berdasarkan faktor pertama, gaji atau upah yang diberikan kepada karyawan harus memenuhi prinsip adil, yang artinya gaji atau upah diberikan berdasarkan tuntutan dan persyaratan pekerjaan, keterampilan yang dimiliki karyawan tersebut dan standar kerja yang telah ditetapkan. Pada faktor kedua, karyawan cenderung menyukai pekerjaan yang memungkinkan mereka menggunakan segenap keterampilan dan kemampuan yang dimilikinya. Karyawan juga menyukai pekerjaan yang memberinya kebebasan dan umpan balik kinerja. Hal tersebut membuat pekerjaan menjadi terasa lebih menantang bagi karyawan. Faktor ketiga, promosi merupakan perpindahan karyawan dari satu posisi ke posisi yang lebih tinggi yang disertai dengan peningkatan tanggung jawab sesuai dengan struktur organisasi. Faktor keempat, bagi sebagian besar karyawan, pekerjaan seringkali digunakan untuk memenuhi kebutuhan sosialnya (kebutuhan untuk berinteraksi dengan orang lain). Oleh karena itu, rekan kerja yang baik, ramah dan kooperatif (dapat bekerjasama) dapat meningkatkan kepuasan kerja seorang karyawan. Faktor kelima, pengawasan memiliki peran penting dalam manajemen. Pada umumnya, karyawan akan merasa senang jika memiliki pengawas (atasan langsung) yang dapat bersikap adil, terbuka, dan kooperatif.

Karyawan yang merasakan kepuasan kerja dalam pekerjaannya, cenderung akan lebih memiliki motivasi untuk menghasilkan kinerja yang lebih baik. Sebaliknya, karyawan yang tidak merasakan kepuasan kerja, cenderung akan mengalami penurunan kinerja akibat tidak termotivasi untuk melaksanakan pekerjaanya dengan baik (Crespi-Vallbona \& Mascarilla-Miró, 2018).

Kepuasan kerja karyawan dapat ditingkatkan melalui pemberian kompensasi yang sepadan atau sesuai dengan usaha yang dikeluarkan dan tuntutan pekerjaan yang dijalankan oleh karyawan tersebut. Mondy \& Martochio (2016) mendefinisikan kompensasi sebagai keseluruhan 
pemberian penghargaan atau imbalan oleh perusahaan sebagai pembayaran atas hasil pekerjaan karyawan.

Perusahaan yang memiliki program kompensasi yang baik dan menarik bagi karyawannya, akan lebih mudah untuk menarik dan mempertahankan karyawan yang memiliki potensi dan kemampuan untuk tetap bekerja di perusahaan serta tidak terpikir untuk pindah ke perusahaan yang lain. Selain itu, dengan program kompensasi yang menarik dan kompetitif tersebut, perusahaan juga dapat memotivasi karyawan agar lebih meningkatkan kinerjanya. Dengan demikian, kompensasi merupakan salah satu kunci perusahaan agar dapat meningkatkan kinerja dan memenangkan persaingan usaha.

Kompensasi pada umumnya dapat berupa kompensasi fisik maupun kompensasi non fisik. Kompensasi biasanya dihitung dan diberikan kepada karyawan sesuai dengan pengorbanan (usaha) yang telah diberikan karyawan kepada perusahaan tempatnya bekerja. Kompensasi langsung umumnya meliputi gaji, upah, komisi, dan bonus, sedangkan kompensasi tidak langsung umumnya meliputi cuti kerja, cuti sakit, liburan dan asuransi kesehatan (Mondy \& Martochio 2016). Pink-Harper \& Rauhaus (2017) mengemukakan bahwa karyawan yang memiliki tingkat pendidikan yang lebih tinggi dan mendapat tingkat pembayaran (kompensasi) yang lebih tinggi, tingkat kepuasan kerjanya akan lebih tinggi.

Selain kompensasi, variabel lain yang dapat dikaitkan dengan kepuasan kerja adalah resiliensi. Resiliensi merupakan suatu konsep yang menggambarkan kemampuan yang dimilili seseorang untuk mengatasi dan melakukan adaptasi terhadap masa-masa sulit yang dihadapinya. Vogus and Sutcliffe (2007) mengemukakan bahwa resiliensi terkait dengan cara organisasi dan indvidu dalam organisasi untuk terus-menerus mencapai hasil yang diinginkan di tengah-tengah kesulitan dan ketegangan yang ada dalam pekerjaan dan organisasi tersebut.

Jackson \& Watkin (2004) berpendapat bahwa resiliensi diri seseorang pada dasarnya dapat menentukan keberhasilan atau kegagalan yang dihadapi orang tersebut dalam kehidupannya. Resiliensi juga dipandang sebagai kemampuan yang dimiliki seseorang untuk dapat bangkit kembali dari situasi atau kejadian yang bersifat tidak menyenangkan atau traumatis. Fonny dkk. (2006) juga berpendapat bahwa resiliensi menggambarkan kemampuan manusia dalam menghadapi dan mengatasi kesulitan (masalah) yang dihadapinya, yang pada akhirnya orang tersebut menjadi kuat atas kesulitan (masalah) yang dialaminya tersebut.

Menurut Amir dan Standen (2012) resiliensi memiliki empat dimensi, yaitu: kegigihan (meliputi kemauan bertahan dan disiplin dalam menghadapi kesulitan), emosi positif (meliputi emosiemosi yang membangkitkan semangat dan menjaga perasaan serta pendengar positif atas kesulitan), pembuatan makna (meliputi cara seseorang yang secara aktif berefleksi dan menegaskan nilai-nilai dan tujuan pribadi dalam menghadapi kesulitan), dan komitmen untuk tumbuh (meliputi seseorang yang dengan sengaja menghadapi kesulitan demi menjadi individu yang lebih baik).

Yuniar dkk. (2011) mengemukakan bahwa resiliensi merupakan salah satu faktor yang sangat diperlukan agar seseorang dapat mengubah berbagai masalah dan kesulitan dalam pekerjaan maupun kehidupannya, sehingga semua masalah dan kesulitannya tersebut pada akhirnya dapat berubah menjadi suatu kesempatan untuk menumbuhkan, mengembangkan, dan meningkatkan kemampuan untuk beradaptasi demi perubahan yang lebih baik. Seseorang yang memiliki resiliensi yang tinggi cenderung dapat mengatasi berbagai permasalahan dan kesulitan dalam 
kehidupannya maupun pekerjaannya. Dengan adanya resiliensi, seseorang (karyawan) dapat melaksanakan tugas dan pekerjaannya dengan lebih ringan, berpikir positif, dan tidak selalu berfokus memikirkan kesulitan yang dihadapinya. Dengan demikian, karyawan tersebut dapat mencapai kepuasan kerja yang lebih tinggi (Nuari, 2016).

\section{Rumusan Masalah}

Pertanyaan yang menjadi rumusan masalah adalah:

a. Apakah kompensasi memiliki pengaruh terhadap kepuasan kerja karyawan?

b. Apakah resiliensi memiliki pengaruh terhadap kepuasan kerja karyawan?

Pernyataan mengenai hipotesis dalam penelitian ini adalah:

H1: Kompensasi memiliki pengaruh positif terhadap kepuasan kerja karyawan.

H2: Resiliensi memiliki pengaruh positif terhadap kepuasan kerja karyawan.

\section{METODE PENELITIAN}

Metode non-probability sampling digunakan sebagai metode pengambilan sampel dalam penelitian ini. Metode non-probability sampling dapat menghasilkan estimasi yang baik berdasarkan karakteristik populasi (Malhotra, 2004). Sampel diambil dengan menggunakan teknik purpose sampling, yaitu sampel diambil berdasarkan suatu pertimbangan atau kriteria tertentu yang telah ditetapkan. Sampel yang dijadikan responden harus merupakan karyawan aktif dengan masa kerja karyawan minimal satu tahun. Sampel yang diambil sebanyak 30 (tiga puluh) orang karyawan. Jumlah sampel sebanyak tigapuluh merupakan persyaratan minimal dalam suatu penelitian, dimana semakin besar sampel akan memberikan hasil yang lebih akurat (Supranto, 2011). Karakteristik responden yang menjadi sampel dalam penelitian ini adalah mayoritas berjenis kelamin laki-laki (64\%), berusia 31-40 tahun (40\%), sudah menikah (70\%), dan memiliki masa kerja 3-5 tahun (65\%).

Tabel 1. Operasionalisasi Variabel

\begin{tabular}{|c|c|c|c|}
\hline Variabel & Definisi & Dimensi & Skala \\
\hline $\begin{array}{l}\text { Kepuasan } \\
\text { kerja }\end{array}$ & $\begin{array}{l}\text { Perasaan senang (positif) seseorang } \\
\text { terhadap pekerjaan }\end{array}$ & $\begin{array}{l}\text { 1. Gaji } \\
\text { 2. Pekerjaan itu sendiri } \\
\text { 3. Promosi } \\
\text { 4. Rekan kerja } \\
\text { 5. Pengawasan }\end{array}$ & Interval \\
\hline Kompensasi & $\begin{array}{l}\text { Segala bentuk pembayaran kepada } \\
\text { karyawan atas hasil kerjanya }\end{array}$ & $\begin{array}{l}\text { 1. Kompensasi langsung } \\
\text { 2. Kompensasi tidak langsung }\end{array}$ & Interval \\
\hline Resiliensi & $\begin{array}{l}\text { Kemampuan mengatasi dan } \\
\text { melakukan adaptasi terhadap } \\
\text { masalah/kesulitannya }\end{array}$ & $\begin{array}{l}\text { 1. Kegigihan } \\
\text { 2. Emosi positif } \\
\text { 3. Pembuatan makna } \\
\text { 4. Komitmen untuk tumbuh }\end{array}$ & Interval \\
\hline
\end{tabular}

Teknik analisis data dalam penelitian ini adalah analisis Partial Least Square (PLS). PLS adalah model alternatif dari covariance-predictive berdasarkan structural equation model (SEM) (Ghozali, 2014). 


\section{HASIL DAN PEMBAHASAN}

Pengujian validitas dan reliabilitas dalam penelitian ini adalah sebagai berikut:

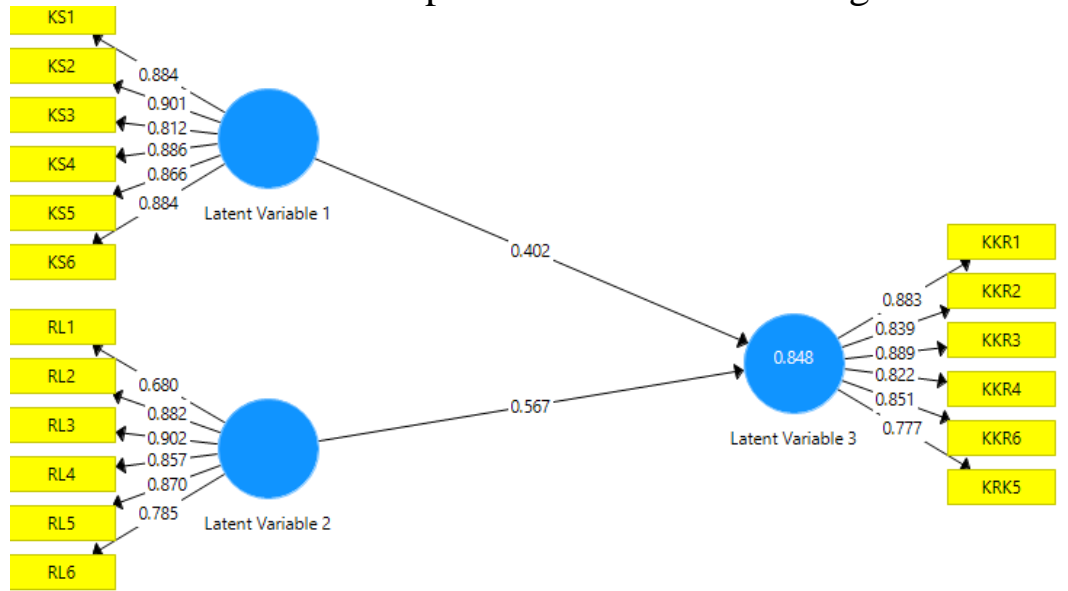

Gambar 1. Output SmartPLS Loading Factor

Pengujian validitas dilakukan pada variabel kompensasi menunjukkan bahwa semua nilai loading factor lebih besar dari 0,5, sehingga dapat dinyatakan bahwa convergent validity untuk variabel kompensasi adalah valid. Pengujian validitas pada variabel resiliensi menunjukkan bahwa semua nilai loading factor lebih besar dari 0,5, sehingga dapat dinyatakan bahwa convergent validity untuk variabel resiliensi adalah valid. Demikian pula pengujian validitas pada variabel kepuasan kerja menunjukkan bahwa semua nilai loading factor lebih besar dari 0,5 , sehingga dapat dinyatakan bahwa convergent validity untuk variabel kepuasan kerja adalah valid.

Tabel 2. Nilai Average Variance Extracted (AVE)

\begin{tabular}{lc}
\hline Variabel & Average Variance Extracted (AVE) \\
\hline Kompensasi & 0.762 \\
\hline Resiliensi & 0.694 \\
\hline Kepuasan Kerja & 0.713 \\
\hline
\end{tabular}

Berdasarkan Tabel 2 diketahui bahwa nilai AVE dari setiap variabel lebih besar dari 0.5, sehingga dapat dinyatakan bahwa semua variabel telah memenuhi persyaratan.

Tabel 3. Hasil Pengujian Reliabilitas

\begin{tabular}{lc}
\hline Variabel & Cronbach's Alpha \\
\hline Kompensasi & 0.937 \\
\hline Resiliensi & 0.910 \\
\hline Kepuasan Kerja & 0.919 \\
\hline
\end{tabular}

Berdasarkan hasil uji reliabilitas yang telah dilakukan, seluruh nilai Cronbach's Alpha dari setiap pernyataan untuk variael kompensasi, resiliensi, dan kepuasan kerja memilki hasil melebihi 0,6. Oleh karena itu, dapat dinyatakan bahwa seluruh variabel yang digunakan dalam penelitian ini telah reliabel. 
Adapun hasil analisis data dalam penelitian ini dapat dilihat dari gambar di bawah ini.

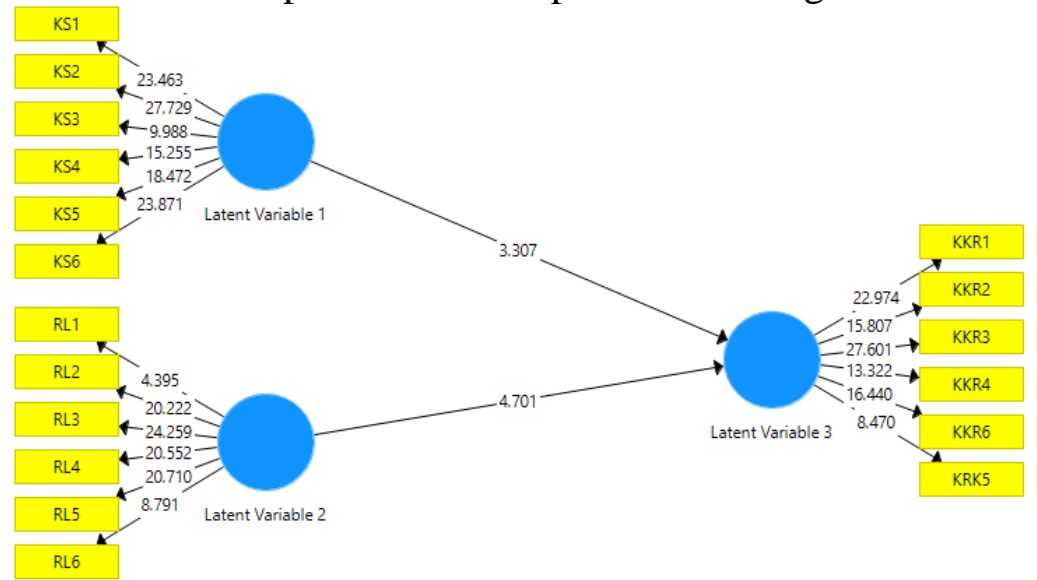

Gambar 1. Output SmartPLS Bootstrapping

Berdasarkan hasil analisis data, dapat diketahui bahwa:

Pada pengujian pengaruh variabel kompensasi terhadap kepuasan kerja, nilai T-Statistics yang diperoleh sebesar 3.307 (lebih besar dari 1,96) dan nilai P Valuenya kurang dari 0.05, maka hipotesis pertama dapat diterima, artinya kompensasi berpengaruh terhadap kepuasan kerja karyawan.

Pada pengujian pengaruh variabel resiliensi terhadap kepuasan kerja, nilai T-Statistics yang diperoleh sebesar 4.701 (lebih besar dari 1,96) dan nilai P Valuenya kurang dari 0.05, maka hipotesis kedua dapat diterima, artinya resiliensi berpengaruh terhadap kepuasan kerja karyawan.

Besarnya nilai koefisien determinasi $\left(\mathrm{R}^{2}\right)$ adalah sebesar 0,848 . Hal ini menunjukkan bahwa sebesar 84,8\% variabel kepuasan kerja dapat dijelaskan oleh kompensasi dan resiliensi, sedangkan sisanya sebesar $15,2 \%$ dijelaskan oleh variabel-variabel lainnya yang tidak termasuk dalam model penelitian ini.

Berikutnya adalah mengenai pengujian Goodness of Fit (GOF), yang bertujuan untuk melakukan penilaian terhadap ketepatan suatu model penelitian. Kriteria Goodness of Fit pada umumnya dinilai berdasarkan nilai Normed Fix Index (NFI). Nilai NFI bertujuan untuk melihat ketepatan suatu model penelitian. Nilai NFI biasanya berada di antara angka 0 sampai dengan angka 1. Apabila nilai NFI mendekati angka 1, maka suatu model dapat dinyatakan baik (Ghozali, 2014). Adapun nilai NFI dalam penelitian ini sebesar 0,734 , yang berarti model dalam penelitian ini sudah dapat dinyatakan baik.

Hal yang tidak boleh dilupakan juga adalah perlu melakukan pengujian multikolinieritas. Model regresi dapat dinyatakan baik apabila dalam model regresi tersebut tidak ditemukan adanya multikolinieritas. Apabila nilai VIF lebih besar dari 10, maka dapat dinyatakan bahwa terdapat multikolinieritas antar variabel bebas. Apabila nilai VIF kurang dari sama dengan 10, maka dapat dinyatakan bahwa tidak terdapat multikolinieritas antar variabel bebas (Sekaran \& Bougie, 2013). Adapun nilai VIF pada variabel kompensasi dan resiliensi sebesar 2,777, yang berarti antar variabel bebas tidak terdapat multikolinieritas.

\section{Pembahasan}

Hasil pengujian pengaruh kompensasi terhadap kepuasan kerja menyatakan bahwa terdapat pengaruh positif kompensasi terhadap kepuasan kerja. Hal tersebut menggambarkan jika 
kompensasi dalam suatu perusahaan ditingkatkan, maka kepuasan kerja karyawan juga cenderung meningkat pula. Hasil penelitian ini sejalan dengan penelitian yang dilakukan oleh Pink-Harper \& Rauhaus (2017) yang mengemukakan bahwa karyawan yang mendapat tingkat pembayaran (kompensasi) yang lebih tinggi, maka tingkat kepuasan kerjanya akan meningkat. Pemberian kompensasi yang sepadan dengan usaha kerja yang diberikan karyawan dalam pekerjaannya akan membuat karyawan merasa dihargai dan senang dalam melaksanakan pekerjaannya, sehingga kepuasan kerjanya dapat meningkat.

Demikian pula dengan hasil pengujian pengaruh resiliensi terhadap kepuasan kerja menyatakan bahwa terdapat pengaruh positif resiliensi terhadap kepuasan kerja. Hal tersebut menggambarkan jika tingkat resiliensi karyawan dalam suatu perusahaan meningkat, maka kepuasan kerja karyawan juga cenderung meningkat. Hasil penelitian ini sejalan dengan penelitian yang dilakukan oleh Nuari (2016) yang mengemukakan bahwa seseorang yang mempunyai resiliensi yang tinggi cenderung dapat mengatasi berbagai permasalahan dalam kehidupannya maupun pekerjaannya. Hal tersebut mendorong seseorang (karyawan) untuk melakukan pekerjaannya melakukan pekerjaannya dengan lebih nyaman dan beban yang lebih ringan. Dengan demikian, karyawan tersebut dapat mencapai kepuasan kerja yang lebih tinggi.

\section{KESIMPULAN DAN SARAN}

Pernyataan mengenai kesimpulan dalam penelitian ini adalah:

a. Kompensasi memiliki pengaruh terhadap kepuasan kerja karyawan.

b. Resiliensi memiliki pengaruh terhadap kepuasan kerja karyawan.

Adapun saran yang dapat diberikan adalah untuk mempertahankan dan bahkan meningkatkan kepuasan kerja karyawan, maka program kompensasi yang tepat, yang telah diterapkan perusahaan pada saat ini dapat terus dipertahankan. Selain itu, untuk meningkatkan tingkat resiliensi karyawan, perusahaan dapat menciptakan pekerjaan yang lebih menantang.

\section{REFERENSI}

Albawi, A.S., Naugton, S., Elayan, M.M., \& Sleimi, M.T. (2019). Perceived organizational support, alternative job opportunity, organizational commitment, job satisfaction and turnover intention: A moderated-mediated model. Organizacija, 52(4), 310-324.

Amir, M. T. \& Standen, P. (2012). Employee resilience in organizations development of a new scale. Paper presented at 26th Australian New Zealand Academy of Management Conference, Perth, Western Australia, Perth. https://www.researchgate.net/publication/263351194_Employee_resilience_in_organizatio ns_Development_of_a_new_scale/link/5acd983c0f7e9b189655cf3c

Crespi-Vallbona, M. \& Mascarilla-Miró, O. (2018). Job satisfaction: The case of information technology (IT) professionals in Spain. Universia Business Review, 58, 36-51.

Fonny, Waruwu, F. E. \& Lianawati. (2006). Resiliensi dan prestasi akademik pada anak tuna rungu. Jurnal Provitae, 2(1), 34-40.

Ghozali, I. (2014). Structural Equation Modeling: Metode alternatif dengan Partial Least Square (PLS). Semarang: Badan Penerbit Universitas Diponegoro.

Hair, J. F., Ringle, C. M. \& Sarstedt, M. (2011). PLS-SEM: Indeed a silver bullet, The Journal of Marketing Theory and Practice, 19 (2), 139 - 151.

Jackson, R. \& Watkin, C. (2004). The resilience inventory: Seven essential skills for overcoming life's obstacles and determining happiness. Selection and Development Review, 20(6), 1424. 
Kong, H. Y., Jiang, X.Y., Chan, W., Zhou, X. G. (2018). Job satisfaction research in the field of hospitality and tourism. International Journal of Contemporary Hospitality Management, 30(5), 2178-2194.

Luthans, F. (2006). Perilaku organisasi. Edisi Sepuluh. Yogyakarta: Penerbit Andi.

Malhotra, N. K. (2004). Marketing research: An applied orientation. New Jersey:

Pearson Education.

Mondy, R. W. \& Martochio, J. J. (2016). Human Resource Management. Fourteenth Edition. Global Edition. London: Pearson Education.

Nuari, N. A. (2016). Quality of work life and job satisfaction of nurses in Amelia Hospital Pare. Jurnal of Ners \& Midwifery, 3(1), 1-7.

Pink-Harper, S. A. \& Rauhaus, B. (2017). Examining the impact of federal employee wellness programs and employee resilience in the federal workplace. Journal of Health and Human Services Administration, 40(3), 353-387.

Sekaran, U. \& Bougie, R. (2013). Research methods for business: A skill building approach. United Kingdom: John Wiley \& Sons Ltd.

Supranto, J. (2011). Pengukuran tingkat kepuasan pelanggan untuk menaikkan pangsa pasar. Jakarta: Rineka Cipta.

Vogus, T. J. \& Sutcliffe, K. M. (2007).” Organizational resilience: Towards a theory and research agenda". IEEE International Conference on Systems, Man, and Cybernetics. 3418-3422.

Yuniar, I. G. A. A., Nurtjahjanti, H. \& Rusmawati, D. (2011). Hubungan antara kepuasan kerja dan resiliensi dengan organizational citizenship behavior (OCB) pada karyawan kantor pusat PT. BPD Bali. Jurnal Psikologi Undip, 9(1), 11-20. 